\title{
QUADRATIC PROGRAMMING: AN OPTIMIZATION TOOL FOR BUILDING GLOBAL MINIMUM VARIANCE PORTFOLIO WITH NO SHORT SALE
}

\author{
Nurwahidah* \\ Department of Mathematics, Faculty of Science and Technology, Universitas Islam Negeri Alauddin Makassar \\ Jl. H.M. Yasin Limpo No.36, Gowa,92113, Indonesia
}

Corresponding Author e-mail: *nurwahidah.abidin@uin-alauddin.ac.id

\begin{abstract}
Quantitative method in portfolio selection is a fascinating issue to make a decision in investment. Portfolio optimization is a very important to manage investment risk. There are many papers dealing with the Markowitz portfolio model, but not all of the papers studied about positive weight portfolio or no short sale constrained portfolio. Positive weight portfolio describes that short sale is allowed for the investor. While, short sale is banned in a certain economic condition due to its ability in decreasing stock market index. Besides, Islamic capital market does not allow speculative transaction such as short selling. Hence, portfolio with no short sale constraint is needed. This study aims to build Global Minimum Variance Portfolio (GMVP) with no short sale constraint. The GMVP with positive asset allocation based on Markowitz model can be built by using quadratic programming with interior point method. The main theory applied in this research is Markowitz portfolio optimization model. Mean and variance of stocks closing price are two things that should be considered in this model. The result shows that the positive weight of GMVP includes $0 \%$ of ADRO shares; 2, 65\% of ANTM shares; 0\% of CTRA shares; 30,27\% of EXCL shares; 37,21\% of ICBP shares; 3,37\% of INCO shares; 13,89\% of KLBF shares; $0 \%$ of PGAS shares; and 12,61\% of PTBA shares.
\end{abstract}

Keywords: Portfolio, Quadratic Programming, Global Minimum Variance.

Article info:

Submitted: $19^{\text {th }}$ January $2021 \quad$ Accepted: $28^{\text {th }}$ April 2021

How to cite this article:

N. Nurwahidah, "QUADRATIC PROGRAMMING: AN OPTIMIZATION TOOL FOR BUILDING GLOBAL MINUMUM VARIANCE PORTFOLIO WITH NO SHORT SALE”, BAREKENG: J. Il. Mat. \& Ter., vol. 15, no. 02, pp. 305-314, Jun. 2021.

This work is licensed under a Creative Commons Attribution-ShareAlike 4.0 International License.
Copyright $\odot 2021$ Nurwahidah Nurwahidah 


\section{INTRODUCTION}

Money is a very important thing in everyday life. People need money to afford basic necessities such as food, clothing, and accommodations. People who are lack of money will try to get loan with the lowest interest, while people who have much money will look for the greatest return investment alternatives. "High risk, high return" is a basic principle in investing. Therefore, investors have to manage investment risks by implementing a risk management strategy named portfolio diversification.

Diversification defined as a risk management strategy where the investors invest money in different asset to minimize the risk of portfolio. Based on the modern portfolio theory, if the number of securities in a portfolio increases, then the portfolio risks decrease [1]. This is corresponding with a basic advice in investment that "Don't put your eggs in one basket". Modern portfolio theory was pioneered by Harry Markowitz in 1952 [2]. Markowitz portfolio model combines assets to maximize the return that investors could obtain in investment portfolio by considering the risk.

There are many papers dealing with the modification of Markowitz portfolio model. One of the modifications is Global Minimum Variance Portfolio (GMVP). GMVP is a kind of stock portfolio that provide the lowest variance appropriate with the budget constraint [3]. In other words, GMVP has the smallest variance among all portfolios for giving investors the lowest risk portfolio. Based on the ability in performing short sale, GMVP consists of two variations; GMVP with short sale and GMVP with no short sale. Short selling is a transaction activity done by an investor who borrows a security and sells it again on the open market with the expectancy it will decrease in value and the investors can close the trade to obtain profit [4]. Short sale is allowed in a portfolio when the weight of an asset is negative. A negative portfolio weight describes that the investor sells the asset by shorting it, instead of buying the asset. Sometimes, short sale is banned in a certain economic condition due to its ability in decreasing stock market index [5]. Besides, Islamic capital market does not allow speculative transaction such as short selling [6,7]. Hence, portfolio with no short sale constraint is needed.

This article deals with the issue of the application of quadratic programming solved by interior point method to build a GMVP with no short sale constraint. The main theory applied in this research is Markowitz portfolio optimization model. Mean and variance of stocks closing price are two things that should be considered in this model. The research objective is finding the optimum allocation or positive weights of the portfolio by minimizing the risk and maximizing the return at the same time. Enriching the empirical studies of portfolio building is the benefit of this research. This study is also expected to be an inspiration in building positive weights portfolio, such as portfolio from sharia capital market. Besides, an investor from a country with a certain economic condition where short sale is not allowed could consider this study to build a portfolio.

A number of portfolios building strategies have been proposed to enrich the empirical studies of the minimum variance portfolio. A. John, A. I. Lagubayom, and A.-P. J [8] built global minimum variance portfolio using matrix approach. P.Boyle [9] studied a solution in positive weight portfolio that is close to the Levy-Roll, but the method required a specific input expected return factor. Besides, many researchers have been done the previous studies about the application of quadratic programming in building a portfolio. $\mathrm{X}$.-L.Wu and Y.-K. Liu [10] applied robust approach in optimizing fuzzy portfolio selection by parametric quadratic programming. A. Yousfat [11] built a portfolio of Malaysia stocks using quadratic approach. M. Praptiningsih [12] applied Markowitz model in building GMVP of Indonesia stock. A. S. Onanaye and P. O. Agbolamagbin [13] applied quadratic programming with simplex method to optimize a portfolio.

This article is arranged as the following. The first section, preliminary contains research rationale and the formulation of research objectives. The explanation of research method is written in section II. The results and discussion are including in section III. The last section contains the conclusion of the research.

\section{RESEARCH METHODS}

\subsection{Data}

The portfolio selection is based on the Jakarta Stock Exchange data. It consists of nine Indonesia firms' stocks from LQ45 index. They are ADRO, ANTM, CTRA, EXCL, ICBP, INCO, KLBF, PGAS, PTBA. This study applied daily closing price data from June 1, 2017 to November 29, 2019. The nine firm 
stock are considered to be in the portfolio because all of them are available in LQ45 index during the range time. Besides, all of the nine firm stock give the positive mean of return. Furthermore, this study also uses BI-7 Day Reverse Repo Rate data that associate with the range time as risk free asset.

\subsection{Return}

Return is defined as the investment money gain or lost over certain period of time [14]. Mathematically, the return of asset is expressed as follows:

$$
R_{t i}=\frac{p_{t i}-p_{t-1 i}}{p_{t-1 i}}
$$

where:

$\boldsymbol{R}_{\boldsymbol{t i}}:$ : the return of asset $\boldsymbol{i}$ at time $\boldsymbol{t}$

$\boldsymbol{p}_{\boldsymbol{t} i}$ : the current closing asset price $\boldsymbol{i}$ index at time $\boldsymbol{t}$

$\boldsymbol{p}_{t-1 i}: \quad$ the previous closing asset price $\boldsymbol{i}$

Expected return of portfolio is the probable return of a portfolio based on past returns [15]. The expected return of portfolio can be expressed as follows:

$$
E\left[R_{p}\right]=\sum_{i=1}^{N} x_{i} E\left[R_{i}\right]=\mu^{T} x
$$

where:

$\boldsymbol{\mu} \quad$ : expected return of each asset $\boldsymbol{j}$ matrix in the portfolio

$\boldsymbol{x} \quad$ : weight of each asset $\boldsymbol{j}$ matrix in the portfolio

$E\left[R_{p}\right]:$ expected return of portfolio

$R_{p} \quad:$ return of portfolio

$N \quad$ : the number of assets in the portfolio

\subsection{Variance and Standard Deviation}

The term of variance is defined as a value that measures the spread among numbers in a data set. Variance is the squared of standard deviation. It is used to determine the volatility of an asset. Portfolio return variance that consist of $\mathrm{N}$ asset is expressed using the following formula:

$$
\sigma_{p}^{2}=\sum_{i=1}^{N} x_{i}^{2} \sigma_{i}^{2}+\sum_{i=1}^{N} \sum_{j=i+1}^{N} x_{i} x_{j} \sigma_{i j}=\frac{1}{2} x^{T} \Sigma x
$$

where:

$\sigma_{i j}:$ covariance of the $i^{\text {th }}$ and $j^{\text {th }}$ assets

$\sigma_{p}^{2}:$ portfolio variance

$x_{i}:$ weight of the $i^{\text {th }}$ asset in the portfolio, $x_{i}=\frac{\text { value of the } i^{\text {th }} \text { investment }}{\text { total value of porfolio }}$

$\Sigma \quad$ : hessian matrix, $\Sigma \in \mathbb{R}^{\mathrm{n} \times \mathrm{n}}$

$x^{T} \Sigma x \geq 0 \forall x$, the hessian matrix $\Sigma$ is a semi-definite matrix. The hessian matrix $\Sigma$ can also assumed as positive definite matrix. Basically, both of the assumptions are applied to express that there are no abundant assets.

\subsection{Optimizing Portfolio Weights}

The main theory applied in this research is Markowitz portfolio optimization model. The assumptions of the model are single period investment; no transaction fees; investor preference is based on expected return and portfolio risk; no short sale constraint.

Quadratic programming is a linearly constrained optimization problem with a quadratic objective function [11]. The general form of quadratic programming is: 


$$
(Q P)\left\{\begin{array}{cc}
\min _{x} & \frac{1}{2} x^{T} \sum x+c^{T} x \\
\text { s.t. } & A x=b \\
& x \geq 0
\end{array}\right.
$$

Based on the general form (4), the value of $x$ will be determined by minimizing the objective function $\frac{1}{2} x^{T} \sum x+c^{T} x$ with $A x=b$ and $x \geq 0$ as the constraints.

where:

$x: n \times 1$ optimization variable vector

$A: n \times m$ constraint coefficient vector

$b: m \times 1$ right-hand side of constraints equation vector

c : $n \times 1$ vector consisting of linear term in the constraint function

$\Sigma$ : Hessian matrix consisting of quadratic term or miscellaneous term of objective function, $\Sigma \in \mathbb{R}^{\mathrm{n} \times \mathrm{n}}$

The mean-variance problem is formulated as the following system:

$$
\left(Q P_{M}\right)\left\{\begin{array}{cc}
\min _{x} & f=\frac{1}{2} x^{T} \sum x \\
\text { s.t. } & \sum_{i=1}^{N} x_{i}=1, i=1, \ldots N \\
& E\left[R_{p}\right]=\sum_{i=1}^{N} x_{i} \times E\left[R_{i}\right] \geq \overline{E\left[R_{l}\right]} \\
& x \geq 0
\end{array}\right.
$$

Based on the optimization problem (5), the weights of each asset $x\left(x_{1}, x_{2}, \ldots, x_{N}\right)$ that minimalized the objective function or the variance $f$ will be determined. There are three constraints in the optimization problem (5):

1. The first constraint denotes that total assets weight of the portfolio is equal to 1 .

2. The second constraint denotes that the expected portfolio return is greater than or equals to expected return. Return of global minimum portfolio is appropriated with the value of variance that is greater than or equals to 0 .

3. The third constraint denotes that the portfolio weights have to be positive or no short sale allowed.

The weight of each assets determined by primal dual interior point method. The optimization problem (4) is written as the follows:

$$
\begin{aligned}
& \min _{x} f=x_{1}^{2} \sigma_{1}^{2}+x_{1} x_{2} \sigma_{12}+\cdots+x_{1} x_{N} \sigma_{1 N}+x_{2} x_{1} \sigma_{21}+x_{2}^{2} \sigma_{2}^{2}+\cdots \\
& +x_{2} x_{N} \sigma_{2 N}+\cdots+x_{N} x_{1} \sigma_{N 1}+x_{N} x_{2} \sigma_{N 2}+\cdots+x_{N}^{2} \sigma_{N}^{2} \\
& \text { s.t } \quad x_{1}+x_{2}+\cdots+x_{N}=1 \\
& E\left(R_{1}\right) x_{1}+E\left(R_{2}\right) x_{2}+\cdots+E\left(R_{N}\right) x_{N}-x_{N+1}=\overline{E\left[R_{l}\right]} \\
& x_{1} \geq 0, x_{2} \geq 0, \ldots, x_{N} \geq 0, x_{N+1} \geq 0
\end{aligned}
$$

$x_{N+1}$ is an addition slack variable for converting inequality to equality.

Constraints (7) and (8) can be written as constraints coefficient matrix, $A$.

$$
A=\left[\begin{array}{ccccc}
1 & 1 & \ldots & 1 & 0 \\
E\left(R_{1}\right) & E\left(R_{2}\right) & \ldots & E\left(R_{N}\right) & -1
\end{array}\right]
$$

Based on the (7) and (8), there is a vector $b$ that can be expressed as follows:

$$
b=\left[\frac{1}{E\left[R_{l}\right]}\right]
$$

The variance covariance matrix is written as follows: 


$$
\left[\begin{array}{cccc}
\sigma_{1}^{2} & \sigma_{12} & \cdots & \sigma_{1 N} \\
\sigma_{21} & \sigma_{2}^{2} & \cdots & \sigma_{2 N} \\
\vdots & \vdots & \ddots & \vdots \\
\sigma_{N 1} & \sigma_{N 2} & \cdots & \sigma_{N}^{2}
\end{array}\right]
$$

In order equation (6) fulfill the quadratic form $f(x)=\frac{1}{2} x^{T} \Sigma x$, then the Hessian matrix $\Sigma$ is expressed like the following matrix.

$$
\Sigma=\left[\begin{array}{cccc}
2 \sigma_{1}^{2} & 2 \sigma_{12} & \cdots & 2 \sigma_{1 N} \\
2 \sigma_{21} & 2 \sigma_{2}^{2} & \cdots & 2 \sigma_{2 N} \\
\vdots & \vdots & \ddots & \vdots \\
2 \sigma_{N 1} & 2 \sigma_{N 2} & \cdots & 2 \sigma_{N}^{2}
\end{array}\right]
$$

The objective of adding 0 in the last row and last column of $\Sigma^{*}$ is to appropriate the Hessian matrix $\Sigma$ with the matrix A column that has been enlarge due to the slack variable.

$$
\Sigma^{*}=\left[\begin{array}{ccccc}
2 \sigma_{1}^{2} & 2 \sigma_{12} & \cdots & 2 \sigma_{1 N} & 0 \\
2 \sigma_{21} & 2 \sigma_{2}^{2} & \cdots & 2 \sigma_{2 N} & 0 \\
\vdots & \vdots & \ddots & \vdots & 0 \\
2 \sigma_{N 1} & 2 \sigma_{N 2} & \cdots & 2 \sigma_{N}^{2} & 0 \\
0 & 0 & 0 & 0 & 0
\end{array}\right]
$$

Lagrange function of optimization problem (5) is expressed as follows:

$$
L(x, v, \gamma)=\frac{1}{2} x^{T} \Sigma x+v^{T}(b-A x)-\gamma \sum_{i} \ln \left(x_{i}\right)
$$

where:

$v$ : Lagrange multiplier

$\gamma:$ multiplier of barrier term

Lagrange function (15) is derived partially to $x$ and $v$, then dual feasibility and primal feasibility condition are obtained consecutively.

$$
\begin{gathered}
\Sigma x-A^{T} v-\gamma X^{-1} e=0 \\
b-A x=0
\end{gathered}
$$

The slackness condition is derived from $\gamma X^{-1} e$ in (16), then:

$$
X U e=\gamma e
$$

where:

$X \quad$ : diagonal matrix of $x_{i}$

$U:$ diagonal matrix of $u_{i}$

$e \quad:$ matrix of ones

Non-linear equation in quadratic programming system is solved by Newton method. Vectors $x, u, v$ are the iteration initial points and the next iteration will be $x+d_{x}, u+d_{u}, v+d_{v}$. The value of $d_{x}, d_{u}, d_{v}$ are obtain by solving the following equation.

$$
\left(\begin{array}{ccc}
A & 0 & 0 \\
-\Sigma & I & A^{T} \\
U & X & 0
\end{array}\right)\left(\begin{array}{l}
d_{x} \\
d_{u} \\
d_{v}
\end{array}\right)=-\left(\begin{array}{c}
A x^{k}-b \\
-\Sigma \mathrm{x}+\mathrm{A}^{\mathrm{T}} \mathrm{v}^{\mathrm{k}}+\mathrm{u}^{\mathrm{k}} \\
X U e-\gamma^{k} e
\end{array}\right)
$$

The distance between the initial value $x, u, v$ and the new value of $x, u, v$ is defined as step length. Mathematically, the step length denotes as following: 


$$
\begin{aligned}
& \alpha_{p}=\beta \operatorname{Min}\left[1,-\frac{x_{i}}{d_{x i}}, d_{x i}<0\right] \\
& \alpha_{d}=\beta \operatorname{Min}\left[1,-\frac{u_{i}}{d_{u i}}, d_{u i}<0\right]
\end{aligned}
$$

The value of parameter $\beta$ is between 0 and 1 . The most frequently used value of $\beta=0,999$. Based from the iteration process, the new value of $x, u, v$ denote as follows:

$$
\begin{aligned}
& x^{k+1}=x^{k}+\alpha_{p} d_{x} \\
& u^{k+1}=\mu^{k}+\alpha_{d} d_{u} \\
& v^{k+1}=v^{k}+\alpha_{d} d_{v}
\end{aligned}
$$

$k$ denotes the number of iterations.

There are three conditions that have to be fulfilled to determine the optimization of the obtained solution. They are feasibility convergence, dual feasibility convergence, and the complementary slackness. If the three conditions are fulfilled, then the Newton's iteration stopped. The three conditions denote in the following expressions. The notation of $\epsilon_{1}, \epsilon_{2}, \epsilon_{3}$ are very small positive numbers and $n$ is the number of optimization variable.

$$
\begin{aligned}
& \frac{\left\|A x^{k}-b\right\|}{\|b\|+1} \leq \epsilon_{1} \\
& \frac{\left\|r_{d}\right\|}{\left\|\Sigma^{*} x+c\right\|+1} \leq \epsilon_{2} \\
& \gamma \leq \epsilon_{3}
\end{aligned}
$$

where:

$r_{d}=\Sigma^{*} x^{k}-A^{T} v^{k}-u^{k}+c$

$\gamma^{k}=\frac{\left(x^{k}\right)^{T} u}{n}$

\section{RESULTS AND DISCUSSION}

This section is representing the result of the data analysis using the concept of building GMVP based on Markowitz model. The result computation of expected return and standard deviation of each asset is contained in the Table 1.

Table 1. Expected return and standard deviation

\begin{tabular}{ccc}
\hline Assets & Expected Return & Standard Deviation \\
\hline ADRO & 0,000015 & 0,026064 \\
\hline ANTM & 0,000272 & 0,025682 \\
\hline CTRA & 0,000179 & 0,026406 \\
\hline EXCL & 0,000585 & 0,028409 \\
\hline ICBP & 0,000507 & 0,014244 \\
\hline INCO & 0,001059 & 0,027041 \\
\hline KLBF & 0,000152 & 0,018316 \\
\hline PGAS & 0,000123 & 0,030786 \\
\hline PTBA & 0,000469 & 0,024724 \\
\hline
\end{tabular}


The result of expected return and standard computation in Table 1 shows that ADRO, CTRA, and PGAS have high standard deviation and low expected return, while the others have high expected return and high standard deviation. Standard deviation in this study denotes asset risk.

There are many combinations of asset weight obtained. All of the asset combinations contained in the Table 1 are consist of efficient portfolio. All portfolios in the efficient frontier are efficient portfolio. Optimal portfolio defined as investor portfolio selected from the efficient portfolio. The optimal portfolio in this study is global minimum variance portfolio. This portfolio is generally optimal because it is not depending on a certain investor preference. Table 2 contains 20 portfolios weight combinations in the efficient frontier.

Table 2. Efficient portfolios combination:

\begin{tabular}{cccccccccc}
\hline Portfolio & & & \multicolumn{7}{c}{ Assets } \\
\hline & ADRO & ANTM & CTRA & EXCL & ICBP & INCO & KLBF & PGAS & PTBA \\
\hline $\mathbf{1}$ & 0,0000 & 0,0265 & 0,0000 & 0,3027 & 0,3721 & 0,0337 & 0,1389 & 0,0000 & 0,1261 \\
\hline $\mathbf{2}$ & 0,0000 & 0,0032 & 0,0000 & 0,3162 & 0,3804 & 0,0611 & 0,1155 & 0,0000 & 0,1236 \\
\hline $\mathbf{3}$ & 0,0000 & 0,0000 & 0,0000 & 0,3276 & 0,3912 & 0,0869 & 0,0761 & 0,0000 & 0,1181 \\
\hline $\mathbf{4}$ & 0,0000 & 0,0000 & 0,0000 & 0,3387 & 0,4023 & 0,1125 & 0,0343 & 0,0000 & 0,1122 \\
\hline $\mathbf{5}$ & 0,0000 & 0,0000 & 0,0000 & 0,3456 & 0,4073 & 0,1433 & 0,0000 & 0,0000 & 0,1038 \\
\hline $\mathbf{6}$ & 0,0000 & 0,0000 & 0,0000 & 0,3338 & 0,3841 & 0,1980 & 0,0000 & 0,0000 & 0,0841 \\
\hline $\mathbf{7}$ & 0,0000 & 0,0000 & 0,0000 & 0,3220 & 0,3609 & 0,2526 & 0,0000 & 0,0000 & 0,0644 \\
\hline $\mathbf{8}$ & 0,0000 & 0,0000 & 0,0000 & 0,3220 & 0,3378 & 0,3073 & 0,0000 & 0,0000 & 0,0448 \\
\hline $\mathbf{9}$ & 0,0000 & 0,0000 & 0,0000 & 0,2984 & 0,3146 & 0,3620 & 0,0000 & 0,0000 & 0,0251 \\
\hline $\mathbf{1 0}$ & 0,0000 & 0,0000 & 0,0000 & 0,2866 & 0,2914 & 0,4166 & 0,0000 & 0,0000 & 0,0054 \\
\hline $\mathbf{1 1}$ & 0,0000 & 0,0000 & 0,0000 & 0,2672 & 0,2595 & 0,4733 & 0,0000 & 0,0000 & 0,0000 \\
\hline $\mathbf{1 2}$ & 0,0000 & 0,0000 & 0,0000 & 0,2449 & 0,2243 & 0,5308 & 0,0000 & 0,0000 & 0,0000 \\
\hline $\mathbf{1 3}$ & 0,0000 & 0,0000 & 0,0000 & 0,2227 & 0,1890 & 0,5883 & 0,0000 & 0,0000 & 0,0000 \\
\hline $\mathbf{1 4}$ & 0,0000 & 0,0000 & 0,0000 & 0,2004 & 0,1538 & 0,6457 & 0,0000 & 0,0000 & 0,0000 \\
\hline $\mathbf{1 5}$ & 0,0000 & 0,0000 & 0,0000 & 0,1782 & 0,1186 & 0,7032 & 0,0000 & 0,0000 & 0,0000 \\
\hline $\mathbf{1 6}$ & 0,0000 & 0,0000 & 0,0000 & 0,1560 & 0,0834 & 0,7607 & 0,0000 & 0,0000 & 0,0000 \\
\hline $\mathbf{1 7}$ & 0,0000 & 0,0000 & 0,0000 & 0,1337 & 0,0482 & 0,8181 & 0,0000 & 0,0000 & 0,0000 \\
\hline $\mathbf{1 8}$ & 0,0000 & 0,0000 & 0,0000 & 0,1115 & 0,0129 & 0,8756 & 0,0000 & 0,0000 & 0,0000 \\
\hline $\mathbf{1 9}$ & 0,0000 & 0,0000 & 0,0000 & 0,0633 & 0,0000 & 0,9367 & 0,0000 & 0,0000 & 0,0000 \\
\hline $\mathbf{2 0}$ & 0,0000 & 0,0000 & 0,0000 & 0,0000 & 0,0000 & 1,0000 & 0,0000 & 0,0000 & 0,0000 \\
\hline & & & & & & & & & \\
\hline
\end{tabular}

The GMVP or minimum variance portfolio obtained from optimization of Markowitz model using quadratic programming contained in the Table 3.

Table 3. Assets' composition of GMVP with no short sale constraint:

\begin{tabular}{cc}
\hline Assets & Allocation \\
\hline ADRO & $0,00 \%$ \\
\hline ANTM & $2,65 \%$ \\
\hline CTRA & $0,00 \%$ \\
\hline EXCL & $30,27 \%$ \\
\hline ICBP & $37,21 \%$ \\
\hline
\end{tabular}




\begin{tabular}{cc}
\hline Assets & Allocation \\
\hline INCO & $3,37 \%$ \\
\hline KLBF & $13,89 \%$ \\
\hline PGAS & $0,00 \%$ \\
\hline PTBA & $12,61 \%$ \\
\hline
\end{tabular}

Based on the computation, it is obtained that ADRO, CTRA, and PGAS have no weight contribution in the portfolio because the three stocks have high value of standard deviation and low expected return. Hence, the stocks are not suitable to be in the portfolio. ICBP has the biggest allocation in the portfolio, because it has the lowest value of standard deviation and the third highest expected return among the stocks in the portfolio. EXCL has the second biggest allocation in the portfolio, because it has the second highest expected return and standard deviation. ANTM has the smallest allocation in the portfolio because the standard deviation is in the fifth rank and the expected return is in the sixth rank. In other words, the standard deviation is quite high for its expected return. Table 3 shows that the GMVP with no short sale constraint is the first portfolio in the Table 2.

Assumed that Rp.100.000.000 is given to build GMVP portfolio with no short sale constraint, then the asset allocation is like the following illustration.

Table 4: Illustration of GMVP asset allocation

\begin{tabular}{ll}
\hline Assets & \multicolumn{1}{c}{ Allocation } \\
\hline ADRO & Rp. 0 \\
\hline ANTM & Rp. 2.650 .000 \\
\hline CTRA & Rp. 0 \\
\hline EXCL & Rp. 30.270 .000 \\
\hline ICBP & Rp. 37.210 .000 \\
\hline INCO & Rp. 3.370 .000 \\
\hline KLBF & Rp. 13.890 .000 \\
\hline PGAS & Rp. 0 \\
\hline PTBA & Rp. 12.610 .000 \\
\hline
\end{tabular}

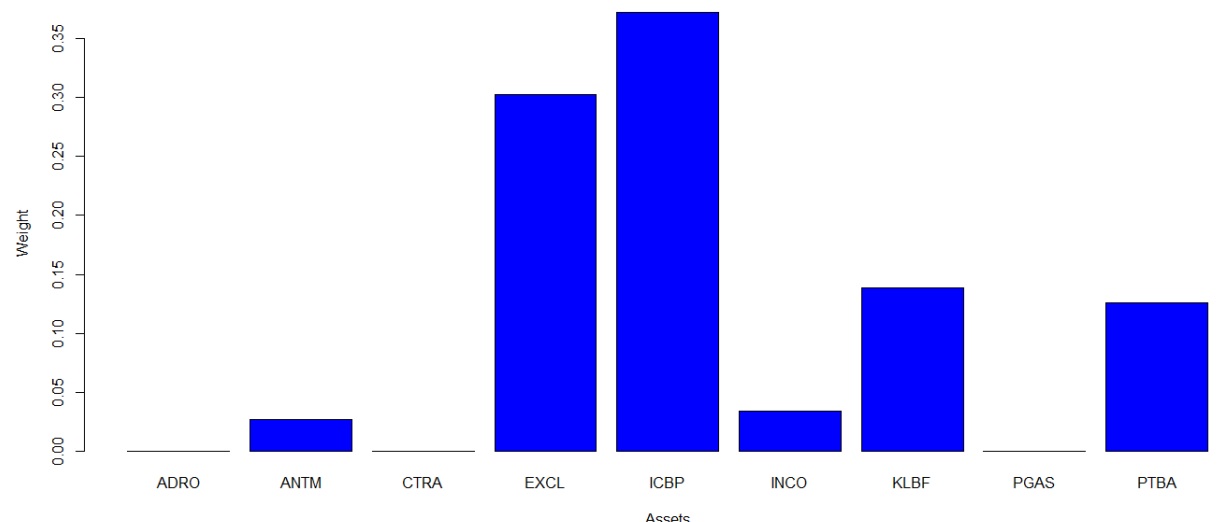

Figure 1. Chart of GMV portfolio with no short sale constraint

Table 5 contains expected return and standard deviation of portfolios corresponding with Table 2 . The GMVP with no short sale constraint (portfolio 1) has the lowest standard deviation and lowest return in the efficient frontier. It means that the portfolio 1 has the lowest risk due to minimizing the variance. Table 5 shows that the expected return of portfolio 1 is 0,0005 which is the smallest expected return value in the 
efficient frontier. While the standard deviation of portfolio 1 is 0,0106 . It is also the smallest value of standard deviation in the efficient frontier.

Table 5: Expected return and standard deviation of efficient portfolios

\begin{tabular}{|c|c|c|}
\hline Portfolio & Expected Return & Standard Deviation \\
\hline $\mathbf{1}$ & 0,0005 & 0,0106 \\
\hline 2 & 0,0005 & 0,0106 \\
\hline 3 & 0,0005 & 0,0107 \\
\hline 4 & 0,0006 & 0,0109 \\
\hline 5 & 0,0006 & 0,0111 \\
\hline 6 & 0,0006 & 0,0115 \\
\hline 7 & 0,0007 & 0,0120 \\
\hline 8 & 0,0007 & 0,0127 \\
\hline 9 & 0,0007 & 0,0136 \\
\hline 10 & 0,0008 & 0,0145 \\
\hline 11 & 0,0008 & 0,0155 \\
\hline 12 & 0,0008 & 0,0166 \\
\hline 13 & 0,0008 & 0,0177 \\
\hline 14 & 0,0009 & 0,0190 \\
\hline 15 & 0,0009 & 0,0202 \\
\hline 16 & 0,0009 & 0,0215 \\
\hline 17 & 0,0010 & 0,0229 \\
\hline 18 & 0,0010 & 0,0242 \\
\hline 19 & 0,0010 & 0,0256 \\
\hline 20 & 0,0011 & 0,0270 \\
\hline
\end{tabular}

Building portfolio with quadratic programming also done by S.G.Filrissa, J.Titaley, and T.Manurung, but the result still contains negative weight of asset in the portfolio [16]. The positive allocation in building portfolio also cannot be obtained with matrix approach [8]. This study aims to build GMVP with no short sale constraint. This study shows that GMVP with positive asset allocation based on Markowitz model can be built by using quadratic programming with interior point method.

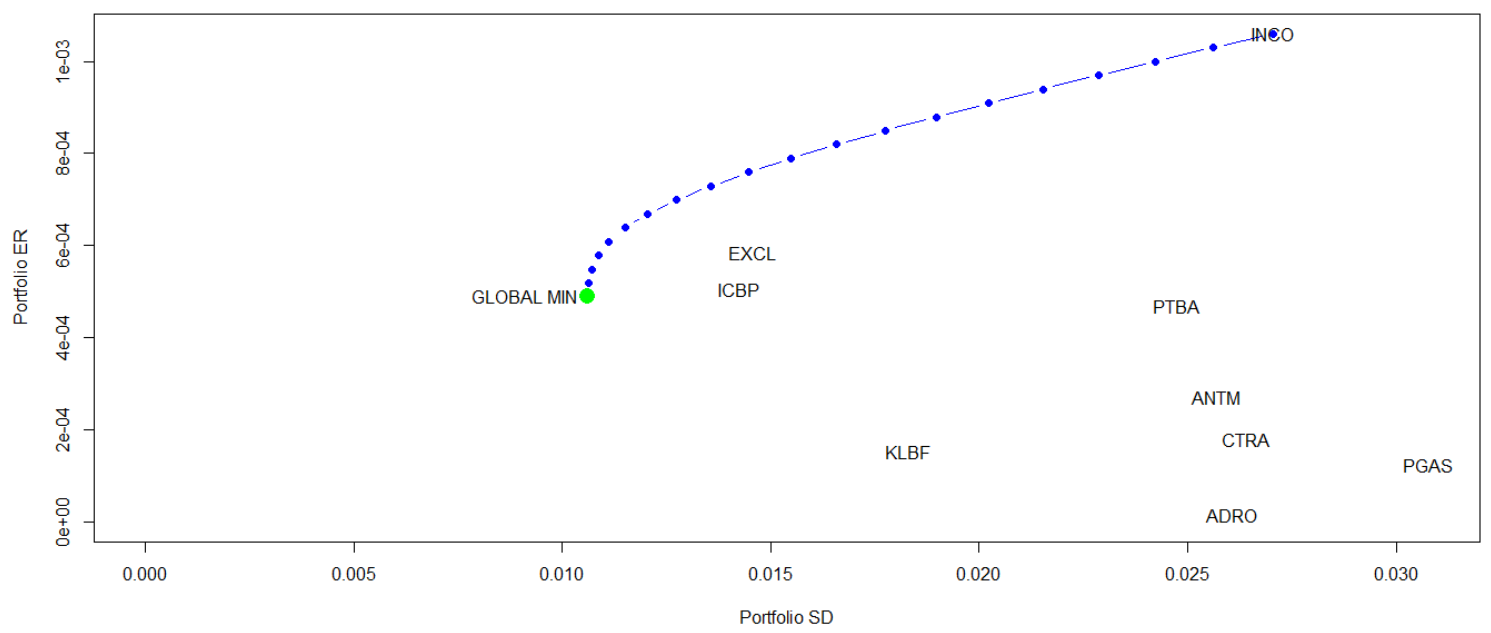

Figure 3: GMVP with no short sale constraint in efficient frontier 


\section{CONCLUSION}

Research shows that quantitative method in portfolio selection is a fascinating issue to make a decision in investment. Quadratic programming solved by interior point methods is a simple method to build a GMVP with no short sale constraint. The expected return and standard deviation are two important things that must be considered for a reasonable result portfolio.

\section{REFERENCES}

[1] A. Ahuja, "PORTFOLIO DIVERSIFICATION IN THE KARACHI STOCK EXCHANGE," Pakistan Journal of Engineering, Technology \& Science, vol. 1, no. 1, Aug. 2015.

[2] F. J. Fabozzi, H. M. Markowitz, P. N. Kolm, and F. Gupta, "Mean-Variance Model for Portfolio Selection," Encyclopedia of Financial Models, Dec. 2012.

[3] T. Bodnar, N. Parolya, and W. Schmid, "Estimation of the global minimum variance portfolio in high dimensions," European Journal of Operational Research, vol. 266, no. 1, pp. 371-390, Apr. 2018.

[4] V. Valenthio, "LEGALITAS SHORT SELLING DALAM PRAKTIK PASAR MODAL DI INDONESIA," JURNAL EDUCATION AND DEVELOPMENT, vol. 8, no. 1, pp. 158-158, Jan. 2020.

[5] W. R. Adawiyah and Najmudin, "Determinan Pelarangan Praktik Short Selling dalam Lingkup Pasar Modal Syariah dan Realitasnya di Indonesia," Jurnal Asy-Syir'ah, vol. 45, no. I, 2011.

[6] A. Faozan, "Konsep Pasar Modal Syariah," Muqtasid: Jurnal Ekonomi dan Perbankan Syariah, vol. 4, no. 2, p. 287, Dec. 2013.

[7] Y. S. Prasetia, "Implementasi Regulasi Pasar Modal Syariah Pada Sharia Online Trading System (SOTS)," Al-Tijary, vol. 2, no. 2, p. 133, Jan. 2018 .

[8] A. John, A. I. Lagubayom, and A.-P. J, "Portfolio Optimization Using Matrix Approach: A Case of Some Stocks on the Ghana Stock Exchange," International Journal of Accounting, Finance, and Risk Management, vol. 2, no. 1, pp. 21-30, 2017.

[9] P. Boyle, "Positive Weights on the Efficient Frontier," North American Actuarial Journal, vol. 18, no. 4, pp. 462-477, Jun. 2014.

[10] X.-L. Wu and Y.-K. Liu, “Optimizing fuzzy portfolio selection problems by parametric quadratic programming," Fuzzy Optimization and Decision Making, vol. 11, no. 4, pp. 411-449, Mar. 2012.

[11] A. Yousfat, "The Portfolio Selection by Using Quadratic Programming Approach Case Study of Malaysia Stock Exchange," International Journal of Engineering and Technology, vol. 7, no. 4, pp. 1361-1369, Sep. 2015.

[12] M. Praptiningsih, "Applying Portfolio Selection: A Case of Indonesia Stock Exchange," Jurnal Manajemen dan Kewirausahaan, vol. 14, no. 1, Apr. 2012.

[13] A. S. Onanaye and P. O. Agbolamagbin, "Quadratic Programming as An Optimization Tool for Portfolio Management," International Journal of Mathematics and Computer Application Research, vol. 6, no. 2, pp. 16-32, Mar. 2016.

[14] D. G. S. P. Pracanda and N. Abundanti, "Pembentukan Portofolio Optimal dengan Menggunakan Model Markowitz pada Saham Indeks IDX30 di Bursa Efek Indonesia," E-Jurnal Manajemen Unud, vol. 6, no. 2, pp. 802-829, 2017.

[15] Z. Maf'ula, S. R. Handayani, and Z. Z. A, "Portofolio Optimal dengan Penerapan Model Markowitz Sebagai Dasar Keputusan Investasi (Studi pada Perusahaan yang Tergabung dalam Indeks LQ-45 Tahun 2014),” Jurnal Administrasi Bisnis, vol. 63, no. 1, pp. 17-23, Oct. 2018.

[16] S. G. Filrissa, J. Titaley, and T. Manurung, "Analisis Portofolio Saham Model Markowitz dengan Menggunakan Quaratic Programming," d'Cartesian: Jurnal Matematika dan Aplikasinya, vol. 8, no. 2, pp. 121-126, Sep. 2019. 